\title{
Frequency reconfigurable monopole antenna with DGS for ISM band applications
}

\author{
Boddapati T. P. Madhav, Shaik Rajiya, \\ Badugu P. Nadh, Munuswami S. Kumar
}

\begin{abstract}
In this article a compact frequency reconfigurable antenna is presented for wireless communication applications of industrial, scientific and medical band (ISM). The proposed antenna model is designed with the dimensions of $58 \mathrm{~mm} \times 48 \mathrm{~mm}$ on FR4 epoxy of dielectric constant 4.4 with the thickness of $0.8 \mathrm{~mm}$. The proposed antenna consists of defected T-shape ground plane, which acts as a reflector. In the design of frequency reconfigurable antenna, BAR 64-02V PIN diodes are used as switching elements and antenna is fed by microstrip transmission line. The proposed antenna can switch at different frequencies $(2.5 \mathrm{GHz}, 2.3 \mathrm{GHz}$ and $2.2 \mathrm{GHz})$ depending on the biasing voltage applied to the PIN diodes. The current antenna showing VSWR $<2$ in the operating band and providing peak realized gain of $3.2 \mathrm{dBi}$. A good matching obtained between expected and the measured results.
\end{abstract}

K e y w or d s: defected ground structure(DGS), frequency reconfigurability, ISM band, PIN diode

\section{Introduction}

Wireless communication is a way to exchange of data from one place to another place through air medium. Antennas play an exceeding appearance in wireless communications. Various types of antennas and various approaches are used in wireless communications for proficient and protected communications. By the rapid variations of wireless communications, there has been a strong significance in reconfigurable antennas due their effectiveness of various functionalities [1]. Reconfigurable antennas are capable to adopt peculiar frequency and radiation description in a controlled process. The reconfiguration in antennas are inclined to enlarge the antenna performance in various states of events or to satisfy dynamical and efficient requirements. Basically, the reconfigurable antennas can change their fundamental resonating frequencies through electrical, mechanical and by other means. Reconfigurable antennas are divided as frequency, pattern, polarization and bandwidth based on their functions. Reconfigurable antennas have been considered since last few years for various applications like a reconfigurable antenna was designed for wireless and space applications [2]. To produce the reconfigurability, planar inverted-F resonator UWB antenna is suggested in [3].

Earlier frequency reconfigurable antenna designs have been proposed to obtain large tuning ranges by using various antenna topologies and tuning elements. In [4], an electrically small PIFA-based design using switches was proposed to obtain continuous large tuning ranges. A different PIFA-based and slot antenna topologies have been used to obtain continuous wide tuning ranges $[5,6]$. From last five years, the special target of the frequency reconfigurable antennas (FRAs) has been on narrow band fre- quency tuning [7]. Many peculiar methods and architectures has been applied to build frequency reconfigurable antennas. Extensive efforts are presently advancing to develop multi radio mobile platforms like mobile internet devices, laptops and smart phones, to locate various wireless services diffused over a wide frequency range.

One way to achieve the reconfigurable features is to vary the surface current distribution with altering the comparable regional structure. By varying the efficient radiated electrical length, feeding position electrically researchers switching the radiating factors [8]. Another approach to achieve reconfigurability is to make use of phased array structure antenna [9]. Array antennas are possessed with many metallic patches, interconnected with MEMs actuators were suggested in [10]. Varactor diodes limiting the frequency switching range so, PIN diodes are preferred by many researchers because these diodes have the acceptable performance at low cost, simple and ease of fabrication. L-shaped slots of frequency reconfigurable antennas using PIN diodes was proposed in [11]. To achieve frequency reconfigurability a triple $\mathrm{H}$-shaped multiple band patch antenna was presented in [12]. Recently the approach of DGS has been developed to upgrade the features of many microwave devices. DGS is implemented in microstrip antennas to attain benefits like mutual coupling reduction and antenna size reduction etc [13]. A coplanar waveguide fed, frequency reconfigurable DGS antenna has been developed in [14]. By using switchable slotted ground structure, a frequency reconfigurable monopole antenna has been presented in [15].

Table 1 shows the comparative analysis of the proposed antenna with the literature. As per the dimension is concerned, the designed antenna occupying compact

* ALRC-R\&D, Department of ECE, Koneru Lakshmaiah Education Foundation, Vaddeswaram, AP, India, btpmadhavuniversity.in 


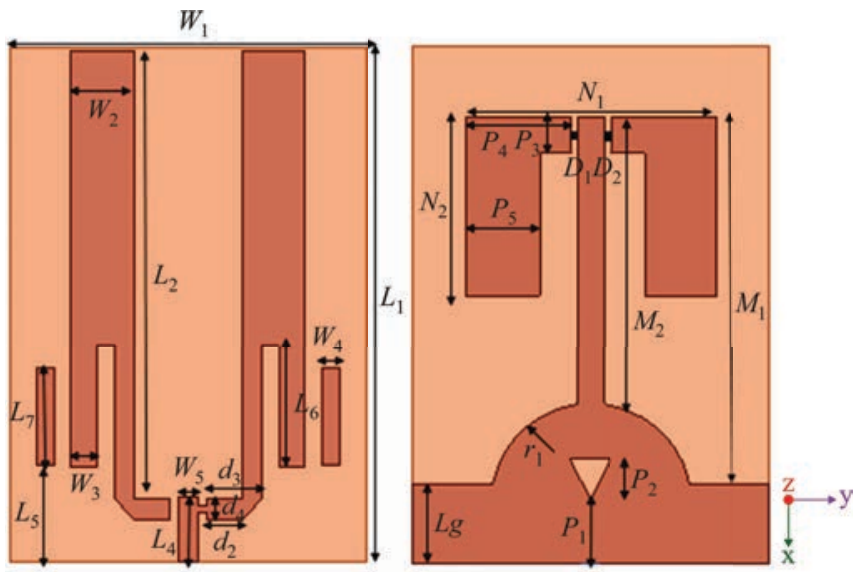

Fig. 1. (a) - front view of antenna, (b) - back view of the antenna
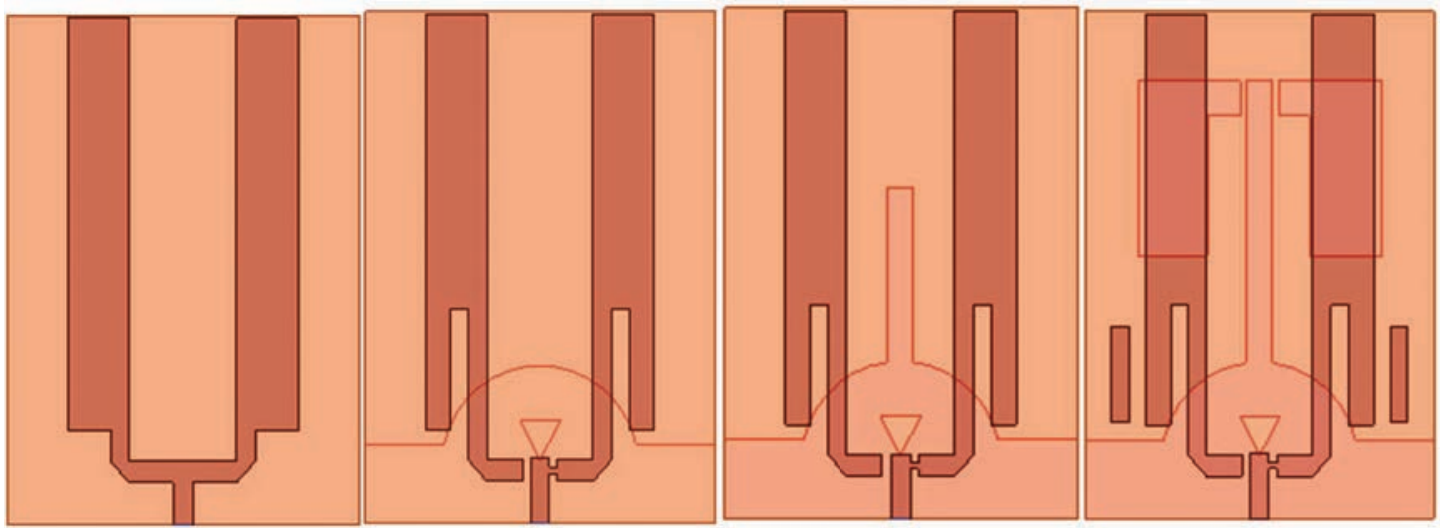

Fig. 2. Iterations of the proposed antenna: (a) - iteration 1, (b) - iteration 2, (c) - iteration 3, (d) - proposed antenna

Table 1. Reference antennas comparison with proposed antenna

\begin{tabular}{|c|c|c|c|c|}
\hline Reference & Shape of the antenna & $\begin{array}{l}\text { Size } \\
(\mathrm{mm})\end{array}$ & $\begin{array}{l}\text { Frequency range } \\
(\mathrm{GHz})\end{array}$ & Applications \\
\hline$[7]$ & Bent half wave dipole & $120 \times 65$ & $1.5,1.44$ & wide tunable range \\
\hline$[9]$ & Antenna array & $95 \times 60$ & $2.05-2.18$ & Mobile terminals \\
\hline$[11]$ & Inverted L-shape microstrip & $50 \times 46$ & $2.2-4.75$ & WiMAX and base station \\
\hline$[12]$ & H-shapes patch antenna & $43 \times 50$ & $0.5-2.5$ & ISM, GSM \\
\hline Proposed & $\begin{array}{l}\text { U-shaped patch with } \\
\text { T-shaped ground plane }\end{array}$ & $58 \times 40$ & $2.2,2.3 \& 2.5$ & Bluetooth, WLAN, ISM \\
\hline
\end{tabular}

size and suitable for applications like Bluetooth, WLAN lower band and ISM band.

In this paper, a novel frequency reconfigurable antenna with DGS is presented. The DGS increases the bandwidth of the antenna and it introduces slow wave effect. DGS will increase the electrical length of the antenna and which helps to reduce the resonant frequency and therefore antenna miniaturization is possible. The designed antenna is efficient of switching at multiple frequency bands around $2.5 \mathrm{GHz}$, which can be used in the systems of industrial, scientific and medical applications, and Bluetooth.

A brief report of design and analysis of proposed reconfigurable antenna is followed by simulation and measured results of proposed antenna parameters return loss, gain, radiation patterns, electric field distributions and surface current distribution.

\section{Antenna design}

Generally, antenna should be compact in nature for present wireless communication systems, to reduce the weight of the devices. The proposed frequency reconfigurable antenna shown in Fig. 1 consisting of dimensions length $\left(L_{1}\right)$ and width $\left(W_{1}\right)$ are $58 \mathrm{~mm} \times 48 \mathrm{~mm}$. The antenna is fabricated on FR4 epoxy substrate with dielectric constant 4.4 and loss tangent 0.02 . The pro- 


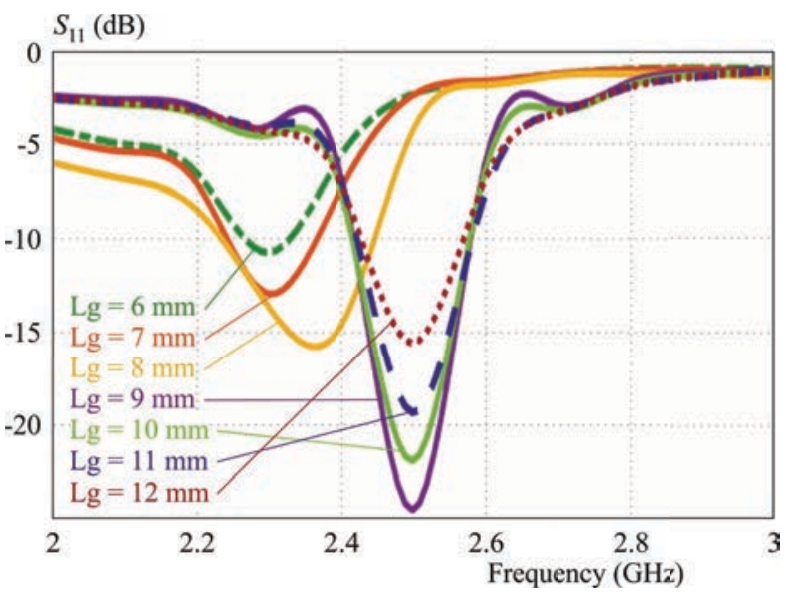

Fig. 3. Simulated parametric analysis by changing the ground length $L_{g}$

Table 2. Dimensions of the proposed antenna

\begin{tabular}{cccc} 
Parameter & $\begin{array}{c}\text { Size } \\
(\mathrm{mm})\end{array}$ & Parameter & $\begin{array}{c}\text { Size } \\
(\mathrm{mm})\end{array}$ \\
\hline$L_{1}$ & 58 & $d_{2}$ & 4.1 \\
$L_{2}$ & 50.5 & $d_{3}$ & 5 \\
$L_{g}$ & 9 & $d_{4}$ & 2.5 \\
$L_{4}$ & 7.3 & $M_{1}$ & 41 \\
$L_{5}$ & 11 & $r_{1}$ & 5 \\
$L_{6}$ & 13.7 & $P_{3}$ & 4 \\
$L_{7}$ & 11 & $N_{1}$ & 28 \\
$W_{2}$ & 7 & $N_{2}$ & 20 \\
$W_{3}$ & 2.9 & $P_{5}$ & 8 \\
$W_{4}$ & 2 & $P_{1}$ & 7.2 \\
$W_{5}$ & 2.2 & $P_{2}$ & 4.5 \\
$P_{4}$ & 11.8 & $W_{1}$ & 48 \\
$M_{2}$ & 32.2 & $h$ & 0.8 \\
\hline
\end{tabular}

posed frequency reconfigurable antenna has one microstrip transmission line, two parallelly loaded symmetrical radiators, one T-shaped ground plane and two rectangle parasitic elements on either side of the radiating patch. These two parasitic radiators relate to the two diodes D1 and D2 and this connection of the diodes can be observed from Fig. 1. The diode switching will make the connection between these two strips to the radiating patch.

Figure 2 presents the iterations of the antenna and Fig. 2(a) shows the radiating patch element with length $\left(L_{2}=50.5 \mathrm{~mm}\right)$ and the width $\left(W_{2}=7 \mathrm{~mm}\right)$. The proposed antenna can switch with reconfigurable frequency bands, by controlling the states at different switching conditions at the ground plane. The microwave transmission line is preferable to reduce the distortion in signal routing and high cross talk in high speed digital PCB designs. To improve impedance matching, rectangular stubs are used. In Fig. 2(b), represents the DGS of the proposed antenna. DGS has been used to improve attributes of several microwave devices. And, to increase the bandwidth

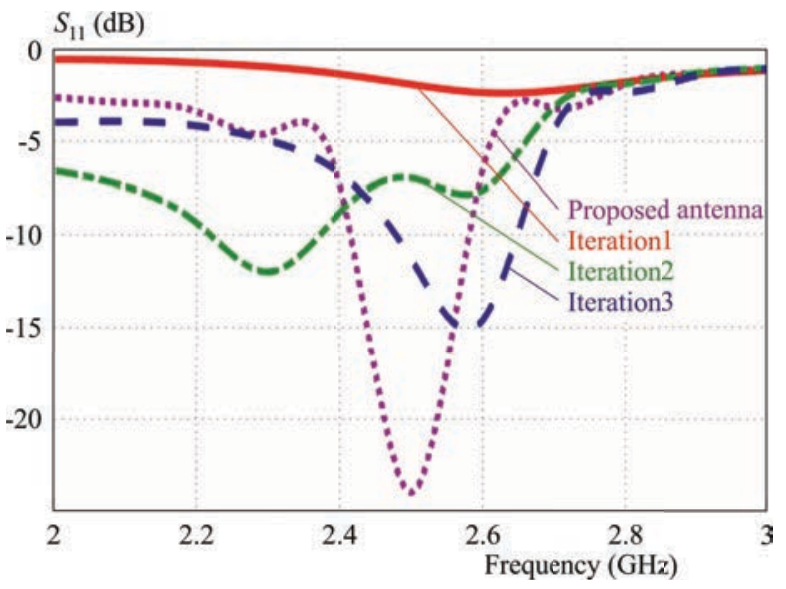

Fig. 4. Simulated return loss of iteration1 to proposed antenna

of the signal. The size of the proposed antenna and mutual coupling is reduced by using DGS. On back view of the proposed antenna there is a semi circle structure, which acts as an impedance transformer between 'M2' and ' $\mathrm{Lg}$ ' as shown in Fig. 2(b). The T-shape defected ground plane is used, and triangular slot is made on the ground structure. The dimensions of the antenna are presented in Table 2. In the iteration 3 of the antenna, a rectangular stub is added in the ground plane and attached to semi-circular ground. In the proposed antenna parasitic elements are added on either side of the rectangular stub in the ground plane. The parasitic elements are non-radiating and are connected through pin diodes and by making the pin diodes in ON/OFF conditions, the parasitic elements are connected and disconnected based on the conditions, this resulting the shift in the frequency.

The length of the patch antenna is calculated by using the formula [16]

$$
L_{2}=\frac{1}{2 f_{r} \sqrt{\varepsilon_{r}} \sqrt{\mu_{0} \varepsilon_{0}}}-2 \Delta L
$$

where $f_{\mathrm{r}}$ is the resonant frequency, $\varepsilon_{\mathrm{r}}$ is the dielectric constant of the material, $\varepsilon_{0}$ is the permittivity of free space and $\mu_{0}$ is the permeability of the free space.

$$
\Delta L=0.412 \frac{\left(\varepsilon_{\text {ref }}+0.3\right)\left(\frac{w_{1}}{h}+0.264\right)}{\left(\varepsilon_{\text {ref }}-0.258\right)\left(\frac{w_{1}}{h}+0.8\right)}
$$

where

$$
\varepsilon_{\mathrm{ref}}=\frac{\varepsilon_{r}+1}{2}+\frac{\varepsilon_{r}-1}{2}\left(1+12 \frac{h}{w_{1}}\right)
$$

and $h$ is the height of the substrate.

Figure 3 shows the parametric analysis of the antenna with change in ground length $L g$. To understand some of the critical parameters that influence the return loss curves, the parametric analysis is done. The ground plane length is varied from $9 \mathrm{~mm}$ to $12 \mathrm{~mm}$. By varying the length of the ground plane, the optimized parameter of $9 \mathrm{~mm}$ is finalized for prototyping. 


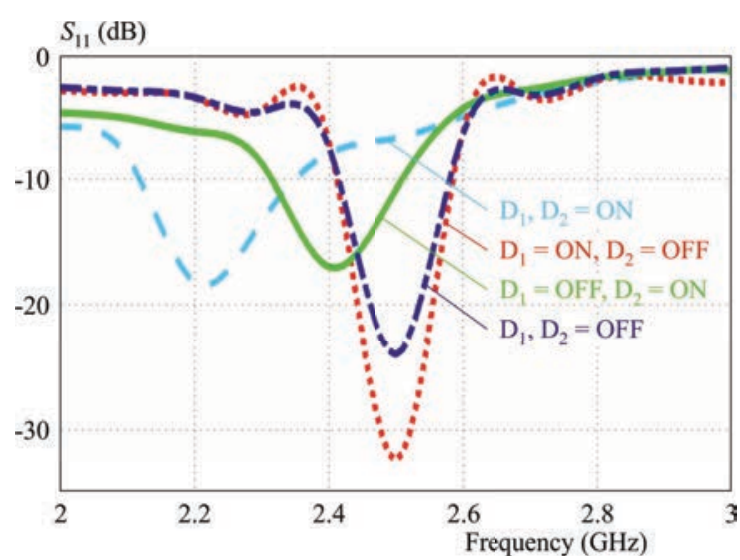

Fig. 5. Simulated reconfigurable condition of the proposed antenna

Table 3. Resonant frequencies $f_{R}$, frequency range $\Delta f$ (in GHz) and gain (in $\mathrm{dB}$ ) for four cases

\begin{tabular}{cccccc} 
Case & D1 & D2 & $f_{R}$ & $\Delta f$ & gain \\
\hline 1 & 0 & 0 & 2.5 & $2.4-2.58$ & 3.2 \\
2 & 0 & 1 & 2.3 & $2.30-2.5$ & 3 \\
3 & 1 & 0 & 2.5 & $2.4-2.58$ & 2.9 \\
4 & 1 & 1 & 2.2 & $2.11-2.35$ & 3.1 \\
\hline
\end{tabular}

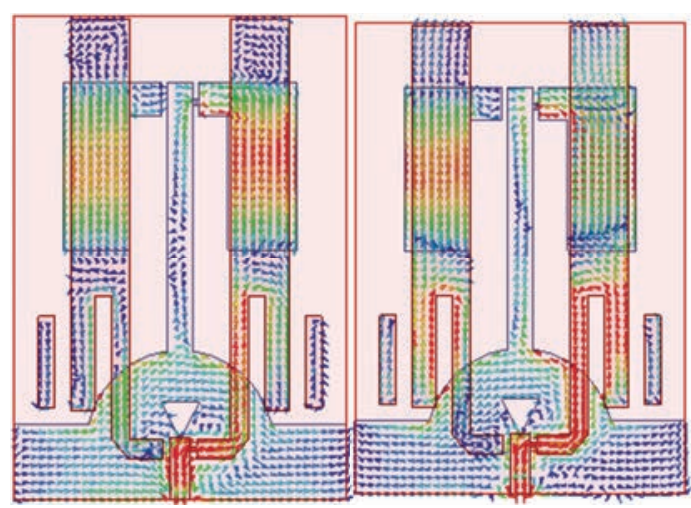

Fig. 7. Simulated surface current distribution of the proposed antenna: (a) - 2.5 GHz (D1 \& D2 OFF), (b) - $2.3 \mathrm{GHz}(\mathrm{D} 1 \mathrm{OFF}$ $\& \mathrm{D} 2 \mathrm{ON}),(\mathrm{c})-2.2 \mathrm{GHz}(\mathrm{D} 1 \& \mathrm{D} 2 \mathrm{ON})$

\section{Results and discussion}

The resolution of designed frequency reconfigurable antenna with DGS in terms of return loss, radiation pattern, input impedance, surface current distribution, and gain is presented by using electromagnetic simulation software HFSS. The four iterations reflection coefficient results of the antenna are presented in Fig. 4. In the first iteration antenna does not show any resonant frequency. In the second iteration the antenna resonates at the single band and operates at the $2.3 \mathrm{GHz}$ and shows the return loss of $-11.8 \mathrm{~dB}$. In this case the antenna is modified by semicircular ground with triangular slot. Further in the next iteration it is modified by placing the stub on the

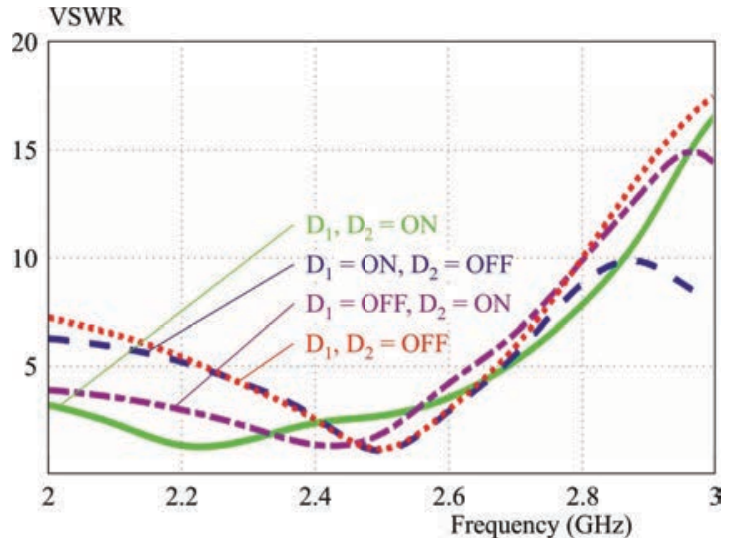

Fig. 6. Simulated VSWR of the antenna at different switching condition

ground structure and for this case the antenna resonating at the $2.5 \mathrm{GHz}$. At this point antenna showing the minimum return loss of $-14.2 \mathrm{~dB}$ and this antenna is further modified with the stubs to form inverted T-shaped ground. The antenna resonates at $2.5 \mathrm{GHz}$ and shows the minimum return loss of $-24.2 \mathrm{~dB}$ with band covering for $2.42-2.58 \mathrm{GHz}$.

To achieve the reconfigurability, two BAR 64-02V PIN diodes are placed in the ground structure. By placing the diodes on either side of the ground structure, four switching conditions are studied as shown in the Fig. 5. When the both diodes D1 and D2 are in OFF condition, the antenna resonates at $2.5 \mathrm{GHz}$. when the diode D1 is $\mathrm{OFF}$ and diode $\mathrm{D} 2$ is $\mathrm{ON}$, the antenna resonates at $2.3 \mathrm{GHz}$. When both the diodes D1 and D2 are in ON condition, the antenna resonates at $2.2 \mathrm{GHz}$, which is presented in Table 3. Figure 6 shows the VSWR of the antenna, which is less than 2 at resonating frequencies based on different switching conditions.

The surface current distribution of the proposed antenna with diodes switching conditions are presented in Fig. 7. The distribution of the radiating elements with respect to the diodes ON and OFF conditions are analyzed from Fig. 7(a) which represents the current distribution of the proposed antenna at $2.5 \mathrm{GHz}$ when the all diodes are in OFF condition and observed that the maximum current is distributed along the feed line. Fig. 7(b) shows current distribution of the antenna when the diodes D1 in $\mathrm{OFF}$ and $\mathrm{D} 2$ in $\mathrm{ON}$ condition and the distribution is maximum along the right-side radiating element. Figure 7 (c) shows the surface current distribution of the proposed antenna when the diode D1 \& D2 in ON condition at $2.2 \mathrm{GHz}$ and the maximum intensity is observed at the radiating patch elements middle portion.

The antenna efficiency depends on the parameter gain. The gain of the proposed antenna with diodes switching conditions are presented in Fig 8. In Fig. 8(a) shows that the gain of the proposed antenna when all diodes are in OFF condition. The gain of the proposed antenna is $3.2 \mathrm{dBi}$ at resonant frequency $2.5 \mathrm{GHz}$. Figure 8(b) shows the gain of the proposed antenna when the diodes D1 in 


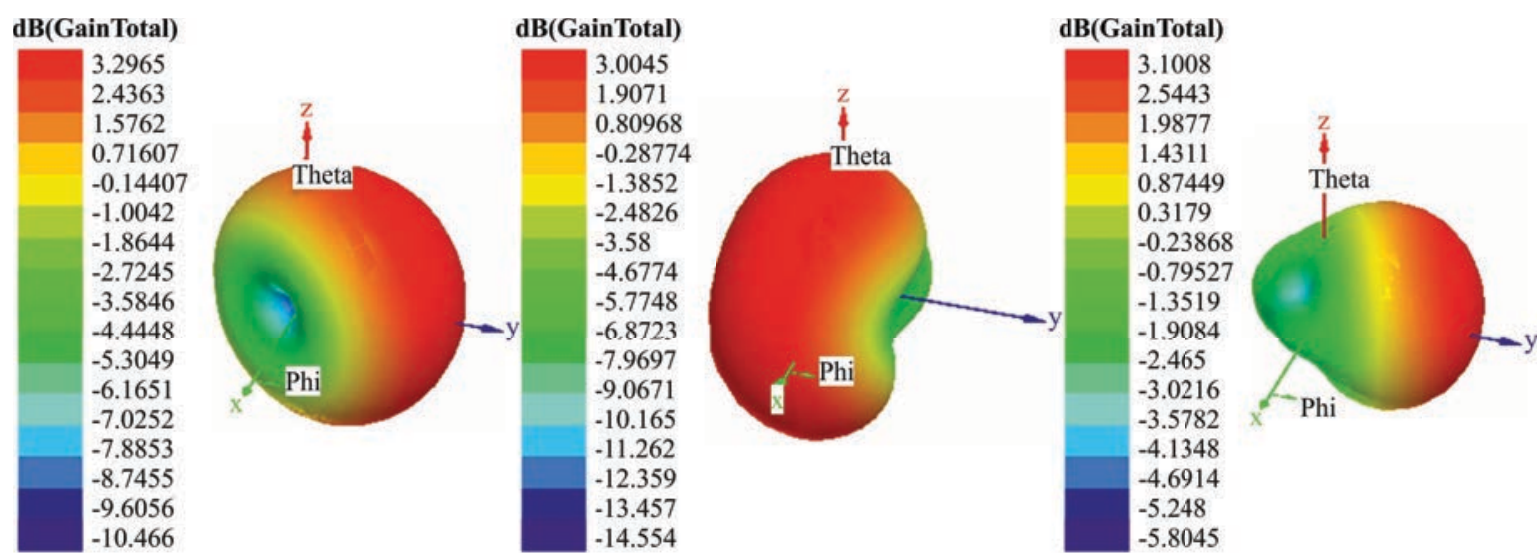

Fig. 8. Simulated 3D-gain of the proposed antenna: (a) - $2.5 \mathrm{GHz}$ (D1 \& D2 OFF), (b) $-2.3 \mathrm{GHz}(\mathrm{D} 1 \mathrm{OFF} \& \mathrm{D} 2 \mathrm{ON})$, (c) $-2.2 \mathrm{GHz}(\mathrm{D} 1 \& \mathrm{D} 2 \mathrm{ON})$

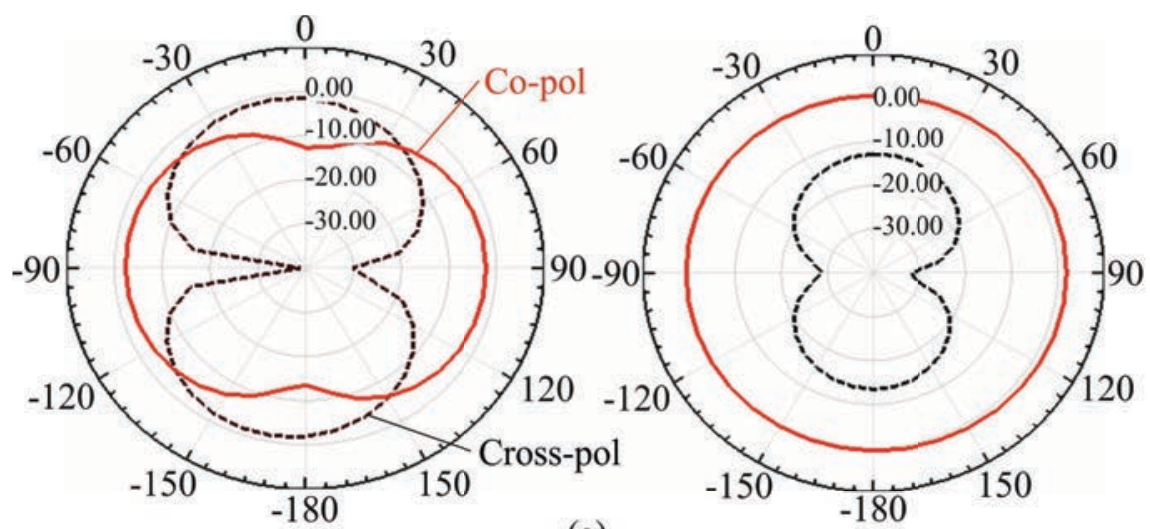

(a)

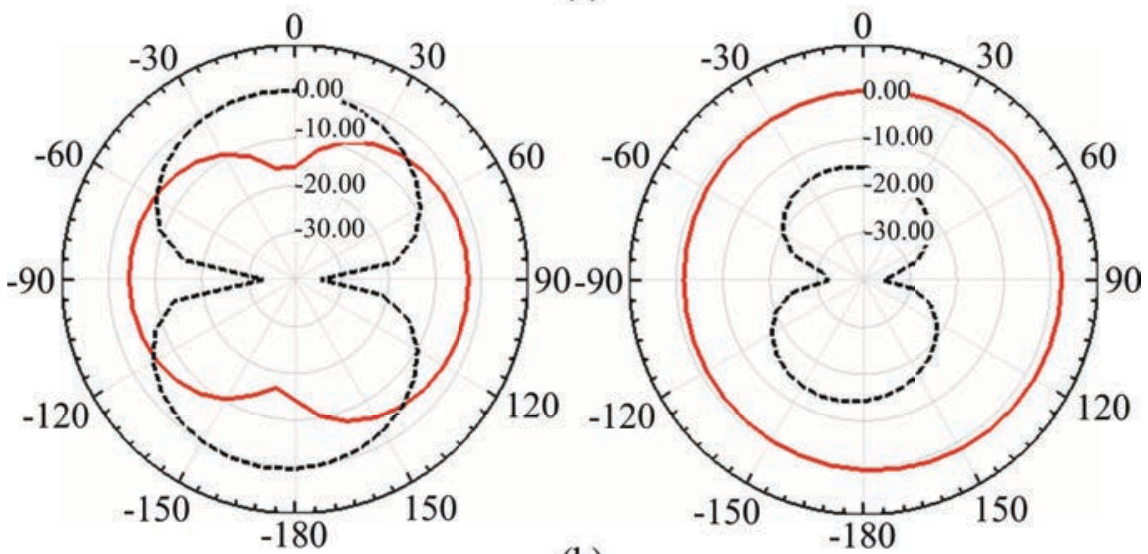

(b)

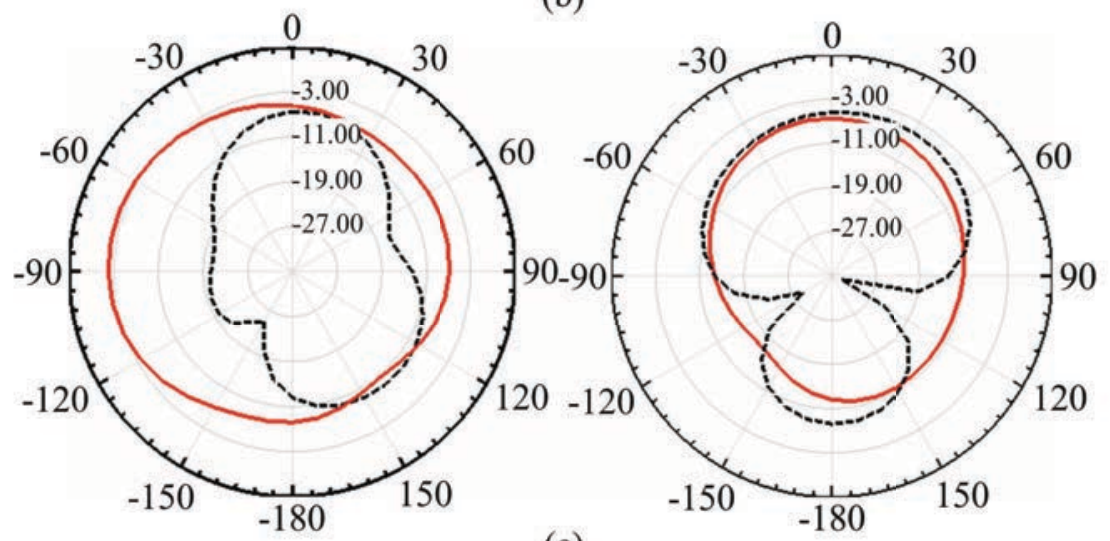

(c)

Fig. 9. Simulated radiation pattern of the proposed antenna in $\mathrm{E}$ and H-planes: (a) $-2.5 \mathrm{GHz}$, (b) $-2.3 \mathrm{GH},(\mathrm{c})-2.2 \mathrm{GHz}$ 

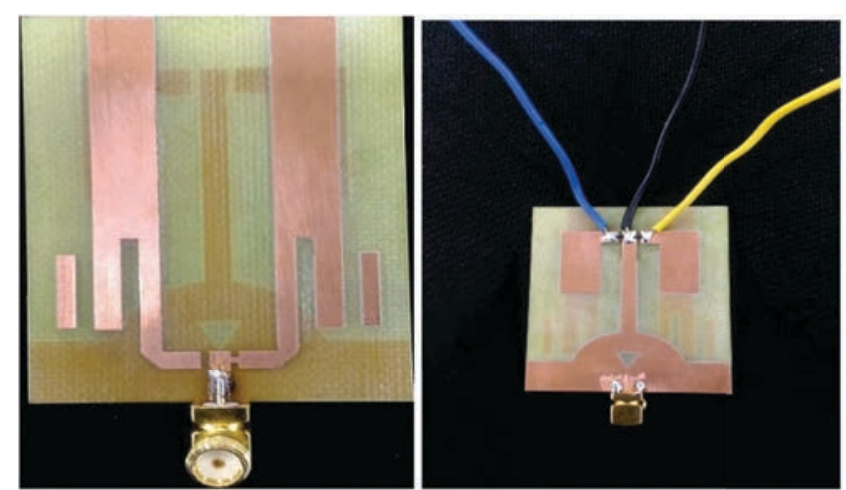

Fig. 10. Prototyped antenna: (a) - front view, (b) - back view with diodes and biasing connection

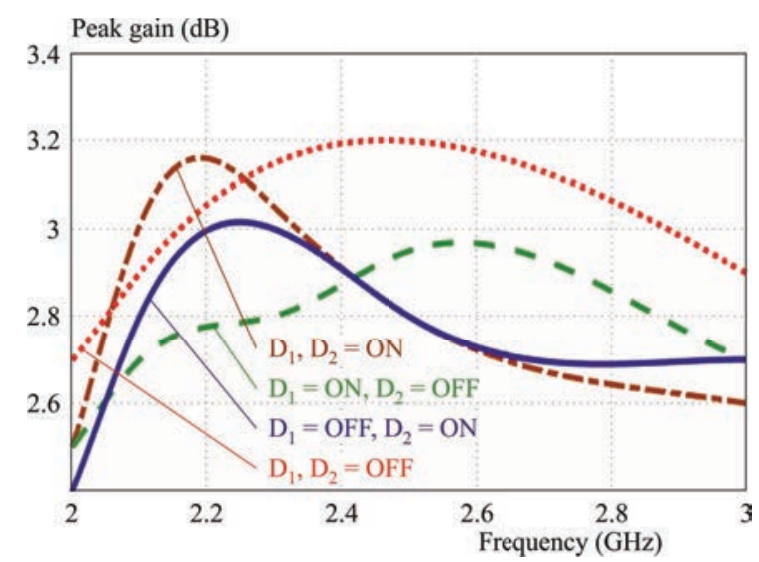

Fig. 12. Measured gain of the antenna with diodes switching

$\mathrm{OFF}$ and $\mathrm{D} 2$ is in $\mathrm{ON}$ condition. The gain of the antenna is $3.0 \mathrm{dBi}$ at resonant frequency $2.3 \mathrm{GHz}$. Figure 8 (c) represents the gain of the proposed antenna when the diodes D1 and D2 are in ON condition. The gain of the antenna is $3.1 \mathrm{dBi}$ at resonant frequency $2.2 \mathrm{GHz}$.

The radiation patterns of the antenna at the resonating frequencies are given in the Fig. 9. The designed antenna radiation characteristics in both E-plane and $\mathrm{H}$ plane are plotted. The E-plane $\left(\Phi=0^{\circ}\right)$ co and cross polarization $(y-z)$ plane and $\mathrm{H}$-field $\left(\Phi=90^{\circ}\right)$ co and cross polarization $(x-z)$ plane at all switches ON and all switches OFF condition are shown in Fig. 9. H-plane has obtained quasi omni-directional radiation pattern with moderate low cross polarization. The inner circles indicate the cross-polarization levels and outer indicates the co-polarization levels.

The proposed antenna is prototyped on FR4 substrate and presented in Fig. 10. Diodes are placed on the ground plane and biasing is provided with connection to power supply. The measured results with VNA shows the applicability of the antenna in real time environment. The measured results of the reflection coefficient with respect to the change in switching is presented in Fig. 11.

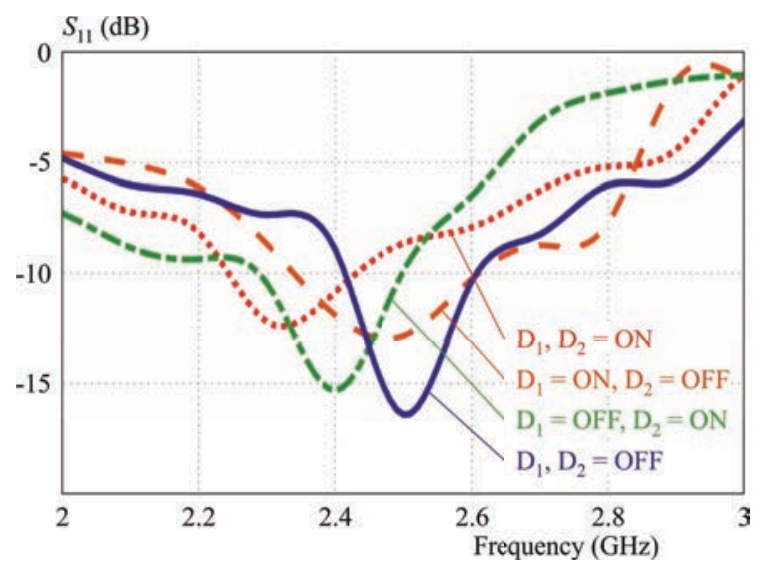

Fig. 11. Measured $S_{1} 1$ with diodes switching

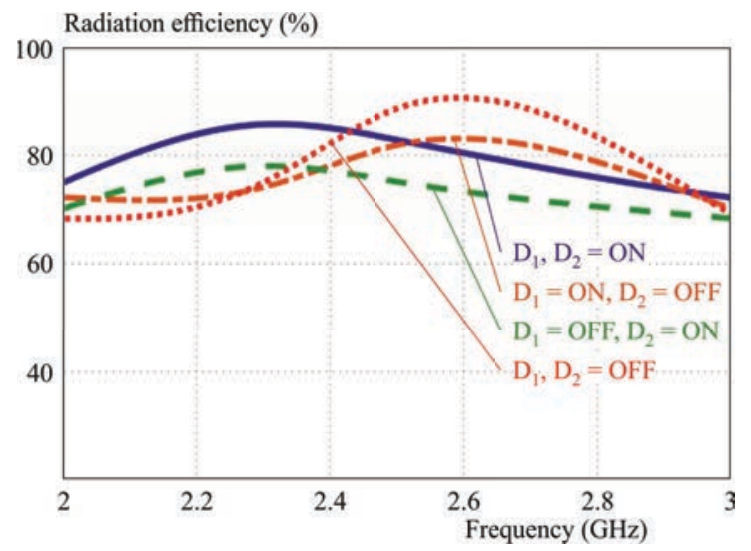

Fig. 13. Radiation efficiency $v$ s frequency of antenna at diode conditions

Figure 12 represents the measured gain of the antenna based on diodes switching. It can be observed that the measured peak realized gain values are in close agreement with the simulated gain values from Fig. 8 .

The efficiency vs frequency is plotted in Fig. 13. Based on the different switching conditions the efficiency of the antenna is varied between 60 to $89 \%$. When the both switches are in $\mathrm{ON}$ condition the maximum efficiency of $89 \%$ is achieved.

\section{Conclusion}

A novel reconfigurable patch antenna with DGS is presented in this article for wireless communication application of ISM band. The designed antenna has compact size of $58 \mathrm{~mm} \times 40 \mathrm{~mm}$ and easy to integrate with implementation. The reconfigurable slot antenna loaded with asymmetric radiators and parasitic elements to attain the require band operation at ISM band, with center frequency $2.4 \mathrm{GHz}$ and $2.5 \mathrm{GHz}$. By placing two diodes with switching between them made frequency shifting and the proposed antenna shows good return loss $\left(S_{11}<-10 \mathrm{~dB}\right)$ at operating bands. A good agreement is obtained between 
simulated and measured results with respect to frequency reconfigurability.

\section{Acknowledgements}

Authors like to express their gratitude to department of ECE of KL University and DST through ECR/2016/000569 and EEQ/2016/000604.

\section{REFERENCES}

[1] Shu-Lin Chen, Pei-Yuan Qin, Can Ding and Y. Jay Guo "Cavity-Backed Proximity-Coupled Reconfigurable Microstrip Antenna with Agile Polarizations and Steerable Beams", IEEE Transactions on Antennas and Propagation vol.65, no. 10, 2017, pp. 5553-5558.

[2] C. G. Christodoulou, "Reconfigurable Antennas for Wireless and Space Applications", Proceedings of the IEEE vol. 100, no. 7, 2012, pp. 2250-2261.

[3] E. Elham, J. R. Kelly and P. S. Hall, "Integrated Wide-Narrowband Antenna for Multi-Standard Radio", IEEE Transactions on Antennas and Propagation vol. 59, no. 7, 2011, pp. 2628-2635.

[4] L. M. Feldner et al, "Electrically Small Frequency-Agile PIFAas-a-Package for Portable Wireless Devices", IEEE Transactions on Antennas and Propagation vol. 55, no. 11, 2007, pp. 3310-3319.

[5] Nguyen Viet-Anh, Rashid-Ahmad Bhatti and Seong-Ook Park, "A Simple PIFA-based Tunable Internal Antenna for Personal Communication Handsets", IEEE Antennas and Wireless Propagation Letters, vol. 7, 2008, pp. 130-133.

[6] P. Bhartia and I. Bahl, "A Frequency Agile Microstrip Antenna", Antennas and Propagation Society International Symposium, IEEE.Vol.20, 1982.

[7] Behdad Nader and Kamal Sarabandi, "Dual-Band Reconfigurable Antenna with a Very Wide Tunability Range", IEEE Transactions on Antennas and Propagation vol. 54, no. 2, 2006, pp. 409-416.

[8] Yu Yufeng et al "An Electrically Small Frequency Reconfigurable Antenna with a Wide Tuning Range", IEEE Antennas and Wireless Propagation Letters vol. 10, 2011, pp. 103-106.

[9] Manteghi Majid, "A Tunable Planar Inverted-f Antenna for Digital Video Broadcast-HandHeld Applications", Microwave and Optical Technology Letters vol. 4, no. 11, 2012, pp. 2635-2638.

[10] Konca Mustafa and P. A. Warr, "A Frequency-Reconfigurable Antenna Architecture using Dielectric Fluids", IEEE Transactions on Antennas and Propagation vol. 63, no. 12, 2015, pp. 5280-5286.

[11] P. Dimitrios, K. Sarabandi and L. P. B. Katehi, "Design of Reconfigurable Slot Antennas", IEEE Transactions on Antennas and Propagation, vol. 53, no. 2, pp. 645-654.

[12] Cai Yaxing, and Zhengwei Du, "A Novel Pattern Reconfigurable Antenna Array for Diversity Systems", IEEE Antennas and Wireless Propagation Letters vol. 8, 2009, pp. 1227-1230,.

[13] M. A. Huda, "A Compact Frequency-Reconfigurable Narrowband Microstrip Slot Antenna", IEEE Antennas and Wireless Propagation Letters vol. 11, 2012, pp. 616-619.
[14] Mustafa Faisal, "Triple H-Shaped Multiple Band Frequency Reconfigurable Patch Antenna", Innovative Computing Technology (INTECH), Sixth International Conference on. IEEE, 2016.

[15] Heba B. El-Shaarawy, "Novel Reconfigurable Defected Ground Structure Resonator on Coplanar Waveguide", IEEE Transactions on Antennas and Propagation vol. 58, no. 11, 2010, pp. 3622-3628.

[16] C. A. Balanis, Antenna theory: Analysis and design, Wiley Publication, 3rd Edition, 2005.

Received 10 July 2018

Boddapati Taraka Phani Madhav was born in India, AP, in 1981. He received the BSc, MSc, MBA, MTech degrees from Nagarjuna University, AP, India in 2001, 2003, 2007, and 2009 respectively. He got his $\mathrm{PhD}$ in the field of antennas from K L University. Currently he is working as Professor and Communication Systems research Head in the Electronics and Communication Engineering. He has published more than 268 papers in International, National journals and Conferences. He is reviewer for several international journals including Elsevier, Springer and Taylor and Francis and served as reviewer for several international conferences. His research interests include antennas, liquid crystals applications and wireless communications. He is a member of IEEE and life member of ISTE, IACSIT, IRACST, IAENG, UACEE and fellow of IAEME. He is the editorial board member for 26 journals. He is acting as Sub-Editor for IJST. He authored seven books and guiding $8 \mathrm{PhD}$ scholars.

Shaik Rajiya pursuing her Masters in the ECE department of K L University. Her area of research includes Reconfigurable antennas, Wireless Body Area Network and Implantable Antennas.

Badugu Prudhvi Nadh received MTech degree in communication systems from Andhra University in 2016. He is currently pursuing Ph.D degree in Electronics and communication Engineering at Antenna and Liquid Crystals Research center of K L Deemed to be University. He is also currently working as Project Assistant for Department of Science and Technology sponsored project. His research interests include Biomedical antennas, Wearable antennas and Reconfigurable antennas for Body area network applications.

Munuswami Siva Kumar (Dr), was born in Vijayawada, India. He received BE in ECE from Periyar University, Tamilnadu, MTech from Bharath University, Tamilnadu, PhD from Gulbarga University, Karnataka. Presently he is working as an Associate Professor in K L Deemed to be University. His research interests include low power VLSI and Antennas.In 2017 he got project form Government funding agencies(SERBScience education research board). He had published papers in various National and International journals and he is a fellow of IETE. 